\title{
GEOSPATIAL IDENTIFICATION OF ALGAL BLOOMS IN INLAND WATERS: A POST CYCLONE CASE STUDY OF CHILIKA LAKE, ODISHA, INDIA
}

\author{
Meghna Sengupta*, R Annadurai, Sachikanta Nanda \\ and Abdullahi Ahmad Datti \\ Department of Civil Engineering, SRM University, Kattankulathur-603203, Tamil Nadu, India \\ *E-mail : meghna.2108@gmail.com
}

\begin{abstract}
Algal blooms are referred to overgrowths of algae in fresh or marine water systems and are caused due to various factors including natural physical and chemical processes and can have severe impacts on human health, aquatic life and even economy in some cases. They flourish in the presence of inorganic nutrients such as nitrogen and phosphorus. This study focuses on identification of algal blooms in inland waters and hence Chilika Lake of Odisha, India is considered as the study area. It is the largest brackish water lake in Asia which was designated as the first Indian wetland of international importance under the Ramsar Convention (1981) for its rich biodiversity. In October 2013, the ecosystem of the lake was affected by a severe cyclone named, "Phailin" leading to increased runoff resulting in the formation of algal blooms. This study has used remote sensing techniques to detect those algal blooms by utilizing satellite imagery which was obtained from EO-1, by the multispectral sensor Advanced Land Imager (ALI). A methodology has been developed by the combination of various image processing techniques like Principal Component Analysis and Normalized Difference Vegetation Index, which proved to be efficient in visualizing the spatial distribution of algal blooms on the lake surface.
\end{abstract}

Keywords: Algal Blooms, PCA, NDVI, Advanced Land Imager, EO-1.

(C) RASĀYAN. All rights reserved

\section{INTRODUCTION}

Chilika Lake has been identified to be of high natural and economic importance due to its rich biodiversity and various fishing practices which support the livelihood of about 150000 fisher folks. In this scenario, the abundance of algal blooms in the concerned ecosystem is quite alarming and demands immediate action. Persisting algal blooms can cause fish mortality, physiological impairments, and various other environmental hazards. The use of remote sensing has been considered for such studies to increase the efficiency and effectiveness in the course of action. Increased occurrences, as well as the severity of algal blooms, could be due to augmentation of required nutrients which results in the flourishing of already existing algae forming major blooms ${ }^{1}$. These nutrients are mostly inorganic compounds consisting phosphorus, nitrogen, and carbon. One of such compounds is sodium carbonate that acts as a catalyst by providing dissolved carbon dioxide that increases photosynthesis leading to blooms. The sources of these nutrients in water systems comprise of natural runoff, household, industrial and agricultural wastes ${ }^{2,3}$, hydro-graphic changes, or climate change impacts.

For this study area, algal blooms evidently flourished as an aftermath of the cyclonic activity that took place in the month of October, 2013. The selected image for the study was acquired about 2 months after the cyclone and hence the spatial distribution of the algal blooms in the lake could be identified.

Several attempts have been made to study algal blooms using remote sensing techniques. In a study, Trichodesmium blooms in the marine waters associated with the Saurashtra coast, Gujarat, India, were studied by utilizing data obtained by the Indian Remote Sensing satellite named, IRS-P4 with the sensor, Ocean Color Monitor (OCM) ${ }^{4}$.

Rasayan J. Chem., 10(1), 234 -239(2017)

http://dx.doi.org/10.7324/RJC.2017.1011585 
False Color Composites generated from bands 8, 6 and $5(865,670,555 \mathrm{~nm})$ exhibited the bloom-forming features. Backscattering signals perceived in the near-infrared band specified the surface index. Another study used MERIS radiance data and predicted pigment concentrations from empirically calibrated Quick Bird data using selected band ratios and principal components analysis ${ }^{5}$. In 1998, NOAA-12 AVHRR imagery was utilized to conduct a reflective investigation which pointed out that blooms spread across $20 \%$ of the surface of the Arabian Sea for approximately a week in May (1995) ${ }^{6}$.

This study focuses on the identification of algal blooms in an inland water body and uses satellite image obtained from the sensor, Advanced Land Imager which is on board the Earth Observing Mission-1 satellite and a methodology was developed using a combination of image processing techniques to identify surface algal blooms visually. With the spatial resolution of 30m (Multispectral) and 10m (PAN), EO-1/ ALI proved to be efficient for the concerned objective of this study.

\section{Study Area}

The study area selected for this study is Chilika Lake, Odisha, India present at south eastern coastal area (Coordinates: $19^{\circ} 43^{\prime} \mathrm{N} 85^{\circ} 19^{\prime} \mathrm{E}$ ). It is the largest brackish water lake in Asia covering an area varying between $900 \mathrm{~km}^{2}$ and $1,165 \mathrm{~km}^{2}$ during the monsoon and summer respectively. In the Ramsar Convention of 1981, Chilika Lake was entitled as the first Indian wetland of international importance. Chilika Lake is a prime fishing zone and a lifeline for the local communities (about 150000 fisher folks of 132 villages and 8 towns) and thus has a high economic importance. It is an estuarine lagoon which is a home to numerous marine, brackish and freshwater species. About a million migratory birds come here during the winters. More than 400 vertebrate species have been recorded in this ecosystem including many rare and endangered species like Irrawaddy dolphins, Olive-Ridley sea turtles, white bellied sea eagles etc. The lake is connected to the Bay of Bengal via a $32 \mathrm{~km}$ long narrow canal which is responsible for fetching saline water into the lake. The freshwater inflow in the lake takes place through the Mahanadi River distributaries on the north and 52 river streams from the west. The lake receives south-west and north-east monsoon with average annual precipitation of 1,238.8 $\mathrm{mm}$. Figure 1 shows the location and extent area for this study.

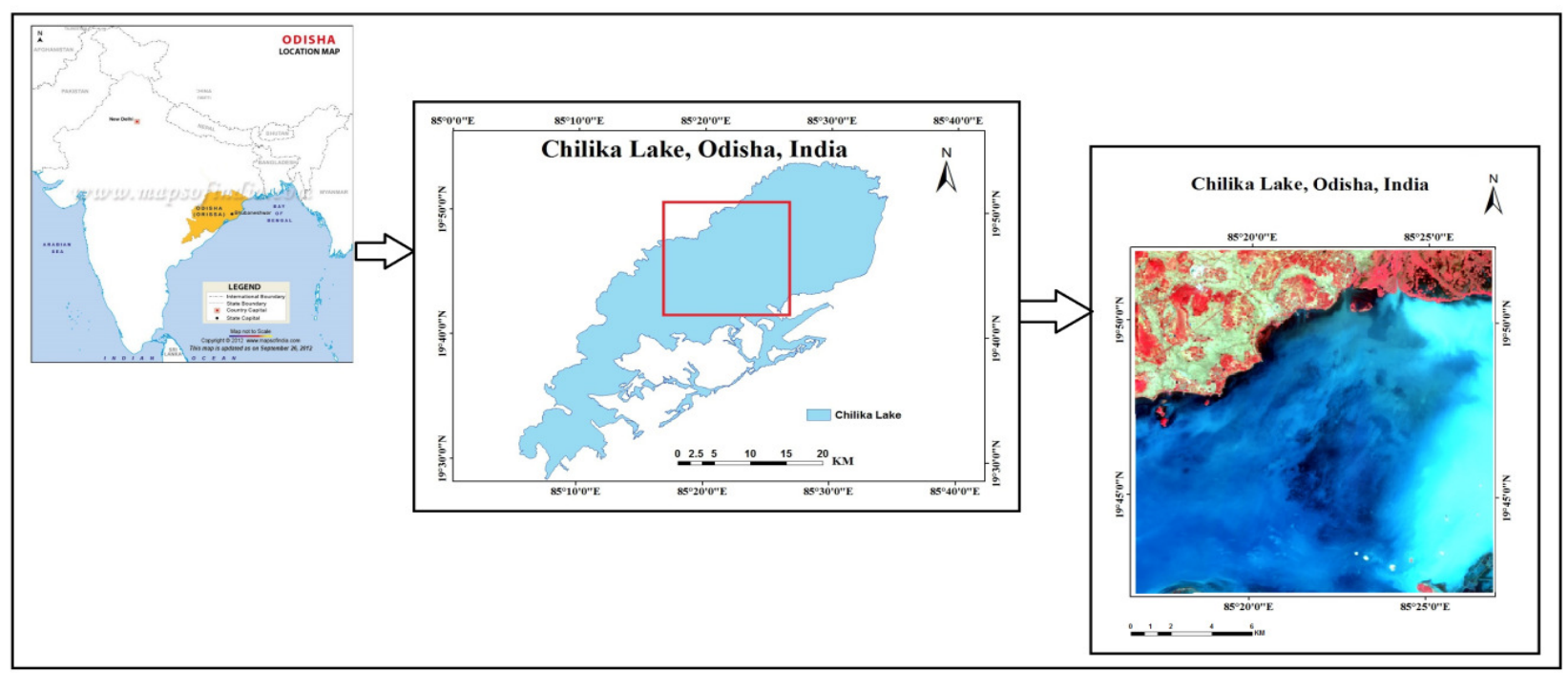

Fig.-1: Location and area extent for study

\section{EXPERIMENTAL}

\section{Data}

Multispectral image obtained from Advanced Land Imager aboard the Earth Observing-1 Mission satellite was used in this study. The image was acquired on 14 December 2013. The Earth Observing-1 Mission (EO-1) satellite was launched in November, 2000 under NASA's New Millennium Program (NMP). The 
RASĀYAN $J$. Chem.

Vol. 10 | No. 1 |234 -239 | January - March | 2017

EO-1 ALI consists of a $15^{\circ}$ Wide Field Telescope (WFT) with a swath width of $37 \mathrm{~km}$. Table-1 shows the detailed specifications of the ALI.

Table-1: EO-1/ ALI Specifications

\begin{tabular}{c|l|c|c}
\hline \multicolumn{2}{|c|}{ Bands } & Wavelength Range $(\mu \mathrm{m})$ & Spatial Resolution $(\mathrm{m})$ \\
\hline Band 1 & Pan & $0.48-0.69$ & 10 \\
\hline Band 2 & Multi Spectral-1' & $0.433-0.453$ & 30 \\
\hline Band 3 & Multi Spectral-1 & $0.45-0.515$ & 30 \\
\hline Band 4 & Multi Spectral-2 & $0.525-0.605$ & 30 \\
\hline Band 5 & Multi Spectral-3 & $0.63-0.69$ & 30 \\
\hline Band 6 & Multi Spectral-4 & $0.775-0.805$ & 30 \\
\hline Band 7 & Multi Spectral-4' & $0.845-0.89$ & 30 \\
\hline Band 8 & Multi Spectral-5' & $1.2-1.3$ & 30 \\
\hline Band 9 & Multi Spectral-5 & $1.55-1.75$ & 30 \\
\hline Band 10 & Multi Spectral-7 & $2.08-2.35$ & 30 \\
\hline
\end{tabular}

Source: United States Geological Survey

\section{Methods}

Several studies have been carried out to understand and harness the capabilities of remote sensing techniques for the identification and monitoring of algal blooms in varying aquatic systems ${ }^{7-9}$. In the current study, identification of blooms in inland waters has been the objective and hence a methodology using remotely sensed data and image processing techniques have been developed.

The study area extent was delineated using ArcGIS 9.1 and the area of interest was extracted from the satellite image. False Color Composite (FCC) of the satellite image was generated to highlight vegetation and water body in the study area using a combination of Band 6, 5 and 4.

Principal Component Analysis (PCA) was carried out for the image ${ }^{10}$ and scatterplot was generated to display the distribution of pixels with respect to two selected variables, in this case, two different bands. Following this, NDVI (Normalized Difference Vegetation Index) ${ }^{11}$ was performed. Mathematically NDVI is given by:

$$
\mathrm{NDVI}=(\mathrm{NIR}-\mathrm{VIS}) /(\mathrm{NIR}+\mathrm{VIS})
$$

Where, NIR represents Near- Infrared and VIS represents Visible Bands. 'Color Map' was produced using 'ENVI Color Tables' to the output imagery of NDVI to highlight the algal blooms spatially. Figure-2 shows the detailed flowchart for the methodology adopted.

\section{RESULTS AND DISCUSSION}

This study aimed to formulate a methodology for the identification of algal blooms in inland waters using remote sensing and GIS. Firstly, the image obtained from the Earth Observing Satellite-1 from its Advanced Land Imager Sensor (ALI) was layer stacked and its FCC image was generated using a combination of Band 6, 5 and 4 and a region of interest was extracted for better observation.

Principal Component Analysis was carried out for the image using ENVI 4.3 which resulted in a reduction of dimensionality and it visibly highlighted the presence of algal blooms Figure-3(a).

Scatterplots represent the variation of pixels for the two bands selected for representation in the $\mathrm{x}$-axis and $\mathrm{y}$-axis and are derived simultaneously from PCA. For this study, the $\mathrm{x}$-axis is assigned as Band 2 which represents 'Green', and the y-axis is assigned as Band 3 which represents 'Blue'. Figure-3(b) shows the generated scatterplot displaying the spatial distribution of pixels representing the presence of algal blooms for images obtained from EO-1/ALI Analysis. The distribution of algal blooms can be clearly observed in the scatterplot. Since algal blooms are signified in the PCA output by blue and green bands; hence a distribution of brightness values conceded by the pixels of these two bands is shown in the scatterplot spatially. 
NDVI (Normalized Difference Vegetation Index) was carried out [Figure-4(a)], following which 'color map' was assigned to the output imagery by using 'ENVI Color Tables'. The algal blooms were highlighted and could be easily observed by varying colors as exemplified in the final output which illustrates the spatial distribution of algal blooms in the lake surface [Figure-4(b)]. 'Red' represents 'high' infestation of algal blooms, yellow represents 'moderate' whereas light green represents 'low' infestation. PCA and NDVI carried out consecutively for the images proved to be an effective methodology to highlight the spread of the algal blooms. Also assigning 'color map' to the output improved the visibility and provided a well-defined depiction.

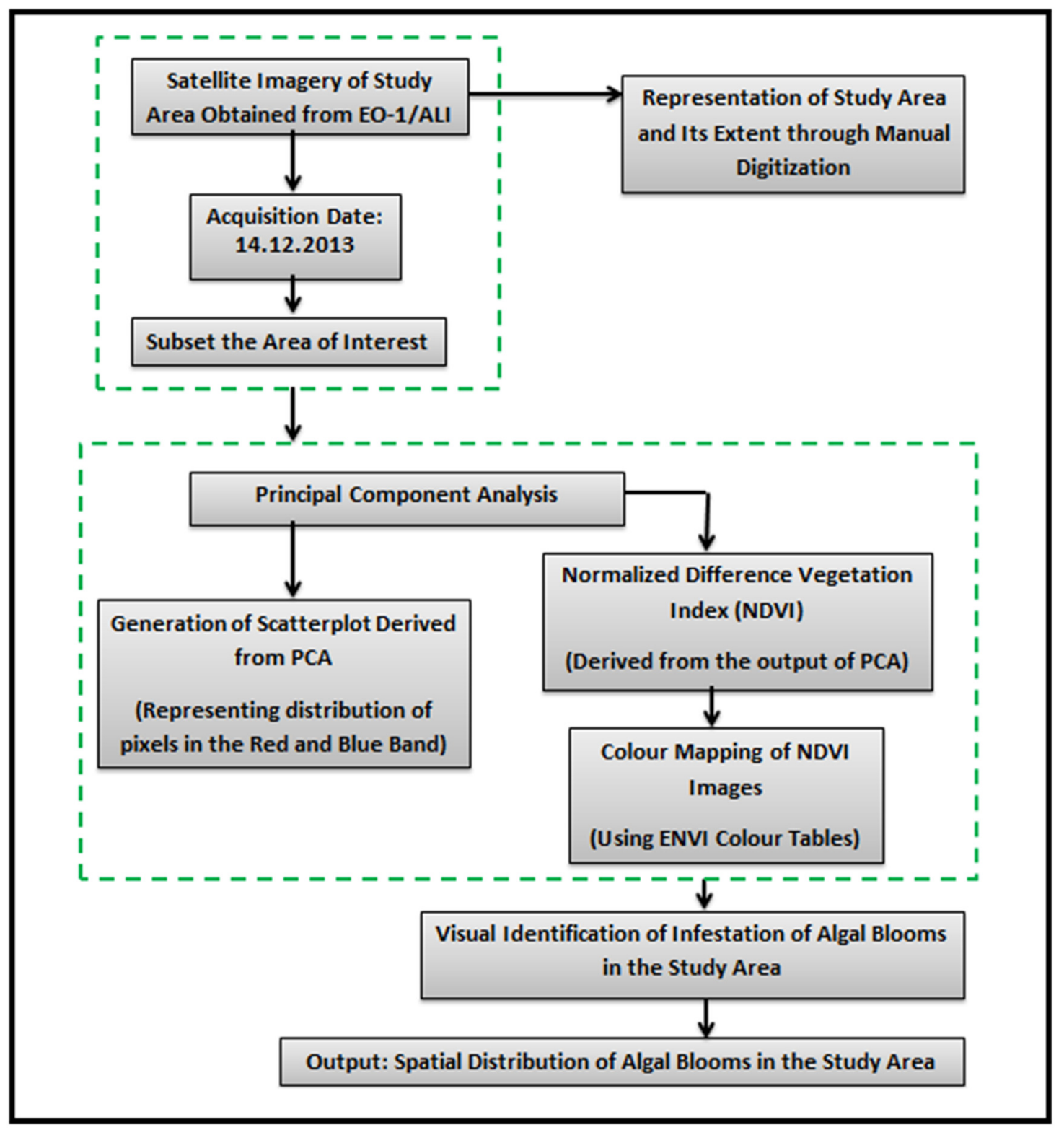

Fig.-2: Flowchart for adopted methodology

In this study, PCA is the preliminary tool which is followed by NDVI which is derived from the output of PCA. PCA enhances and displays prominent pixels and diminishes redundant information and hence allows prominent visualization. NDVI uses a ratio of NIR and RED bands to discriminate vegetation (in this case, algal blooms) from other features. Evaluation of NDVI for a certain pixel results in numeric 
RASĀYAN $J$. Chem.

Vol. 10 | No. 1 |234 -239 | January - March | 2017

values between ' -1 ' to ' +1 ' defining vegetation health and density according to absorption in visible range and reflection in the NIR range for healthy vegetation and vice versa for sparse vegetation. The combination of PCA and NDVI enhanced the image and algal blooms could be visually identified.
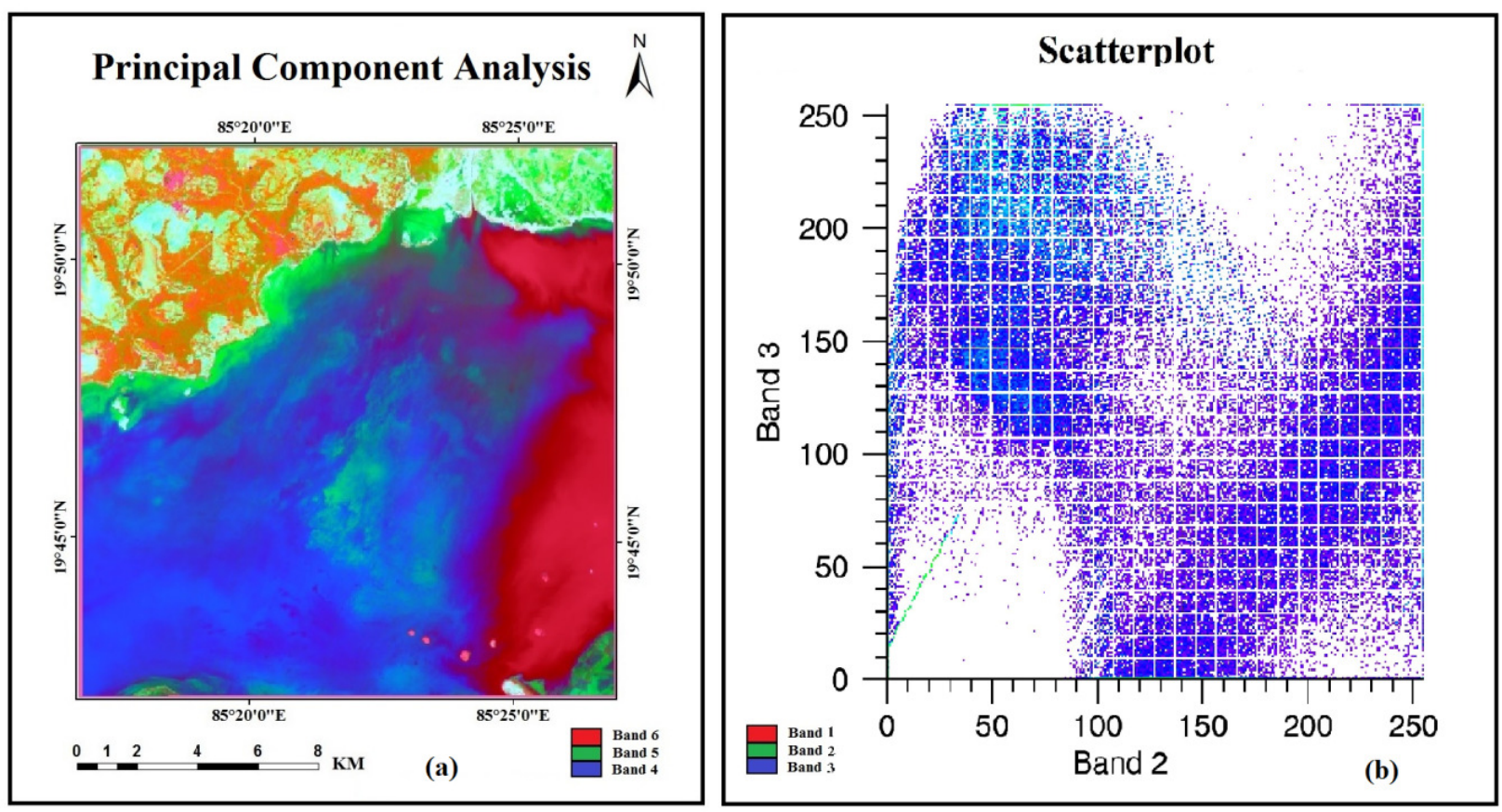

Fig.-3: (a) Principal Component Analysis (PCA) of satellite image obtained by ALI/EO-1 on 14 December 2013 (b) Scatterplot obtained from the PCA of satellite image obtained by EO-1/ ALI on 14 December 2013
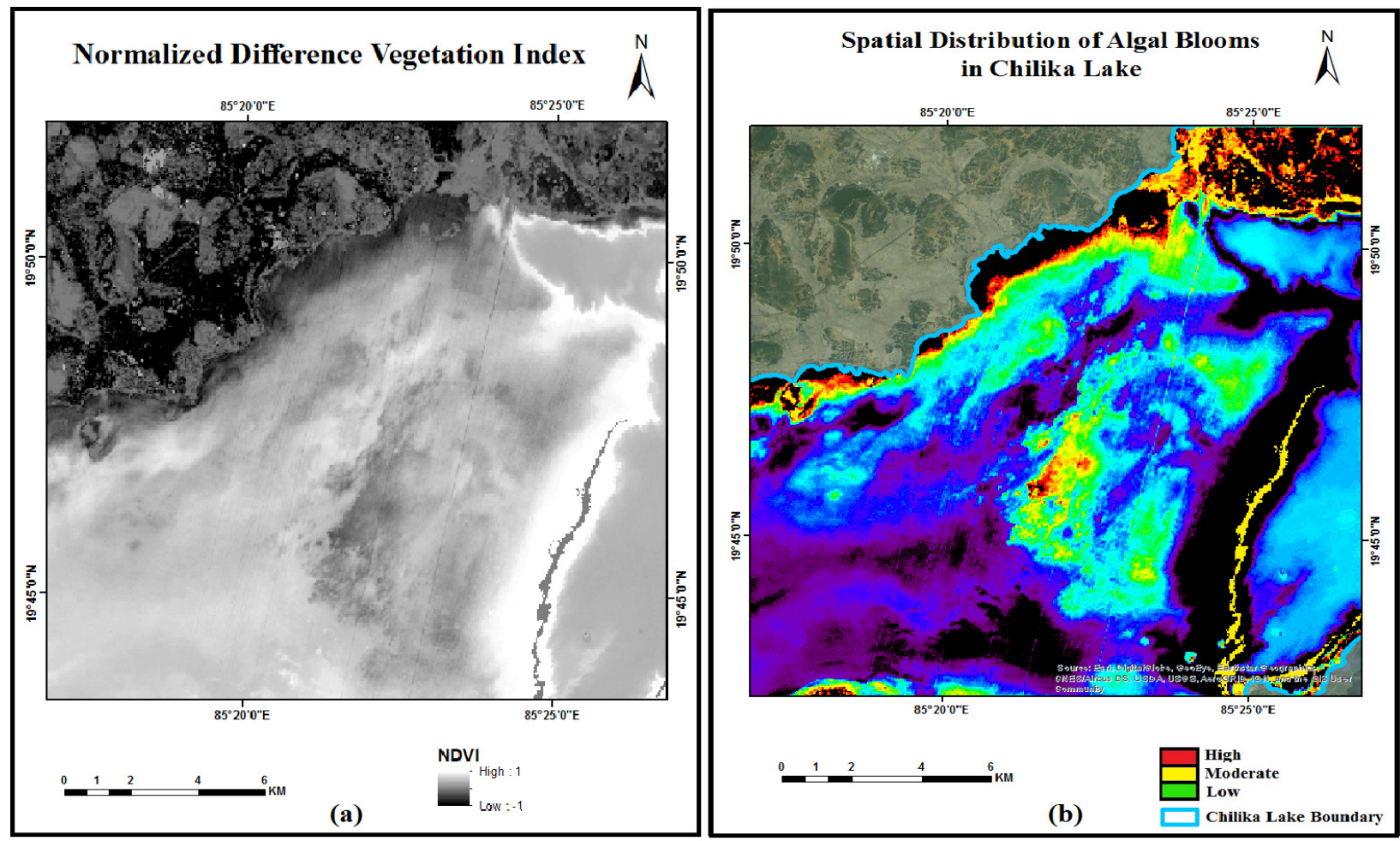

Fig.-4: (a): NDVI derived from the output of PCA of satellite image obtained by ALI/EO-1 on 14 December 2013 (b) Spatial Distribution of Algal Blooms in Chilika Lake (Overlay on Base map provided by ESRI in ArcGIS) 
RASĀYAN J. Chem.

Vol. 10 | No. 1 |234 -239 | January - March | 2017

The sensor, Advanced Land Imager (ALI) has a high signal-to-noise ratio and wide spectral range ${ }^{12}$ and thus showed efficiency in this study which majorly dealt with spectral characteristic of the data for the multiple image processing techniques used. The use of remote sensing to visually detect surface algal blooms in inland waters makes the study time efficient and economical. The results produced from this study can be used to visually recognize the spatial distribution of surface algal blooms in the concerned inland lake and by means of this approach, monitoring of such blooms can be carried out for similar ecosystems.

\section{CONCLUSION}

This study was carried out successfully and the spatial distribution of algal blooms was identified in the study area. Also, they were represented in the form of scatterplots for better understanding. When cyclone, "Phailin" hit the area in October 2013, it underwent a major catch of freshwater and freshwater algal blooms spread rapidly which is evident in this study. Also, runoff from adjacent agricultural farms streamed into the water system providing abundant nutrients for overgrowth of algae. Processing the images with NDVI and Principal Component Analysis (PCA) proved to be useful in the spatial identification of algal blooms in the study area. 'Color map' assigned to the final output facilitated in the depiction of the spatial distribution of infested areas. A larger extent of the study area can be considered and a wider temporal timeline can be taken for further study. This study can be a valuable contribution to the governing bodies responsible for the maintenance and management of the inland ecosystem and provide a better understanding of the degree of concern.

\section{REFERENCES}

1. A. Simon and P. Shanmugam, Advances in Remote Sensing, 1, 35 (2012)

2. R. Ramasubramani, R. Praveen and K. S. Sathyanarayanan, Rasayan J. Chem., 9(4), 715 (2016)

3. G. Babu Rao, M. Krishna Prasad, K. Kishore Kumar and Ch.V.R.Murthy, Rasayan J. Chem., 9(3), 373 (2016)

4. R. K. Sarangi, P. Chauhan and S. R. Nayak, Current Science, 86(12) (2004)

5. S. M. Wheeler, L.A .Morrissey, S. N. Levine, G. P. Livingston and W. F. Vincent, Journal of Great Lakes Research, 38, 68 (2012)

6. D. G. Capone, A. Subramaniam, J. P. Montoya, M. Voss, C. Humborg, A. M. Johansen, R. L. Siefert and E. J. Carpenter, Marine Ecology Progress Series, 172, 281 (1998)

7. T. Kutser, M. Liisa, N. Strombeck and E. Vahtma, Coastal and Shelf Science, 67, 303 (2006)

8. R. P. Stumpf, Human and Ecological Risk Assessment, 7(5) (2001)

9. N. Peetabas and R. P. Panda, International Journal of Scientific and Research Publications, 5(7) (2015)

10. H. Hotelling, J Educ Psychol, 25, 417 (1933)

11. J. W. Rouse, R.H. Haas, J. A. Schell and D. W. Deering, 3rd ERTS Symposium, NASA SP-351, Washington DC, 309 (1973)

12. S. L. Powell, D. Pflugmacher, A. A. Kirschbaum, Y. Kim and W. B. Cohen, Journal of Applied Remote Sensing, 1, 012506 (2007)

[RJC-1585/2017] 